\title{
CIÊNCIA E RELIGIÃO
}

\author{
INTRODUÇÃO
}

João Carlos Salles*

Ciência e religião parecem termos opostos e inconciliáveis. Não por acaso, procurando muitas vezes anular-se reciprocamente, os termos se conservam, em muitos sentidos, como complementares. Assim, suas dimensões se atraem e se repelem mutuamente, talvez por sua natureza, em ambos os casos, visar à universalidade, cobrando ambas dos praticantes uma adesão íntima. Em muitos momentos, parecem constituir visões de mundo incomensuráveis, cujos interesses e procedimentos levariam a respostas e problemas imiscíveis. Por vezes, porém, parecem conviver e, mesmo, se solicitar, como se, juntas, satisfizessem a necessidades da vida humana. Não raro, um campo almeja a suficiência por caminhos perigosos, como os que levam a idolatrar a razão, chamada, então, a proferir respostas científicas aos mistérios da vida, ou os que, ao contrário, pretendem limitar a investigação científica, em função de acordos que sequer passariam pela manifestação dos inte-

* Doutor em filosofia. Professor da Universidade Federal da Bahia com pesquisa apoiada pelo CNPq e pela FAPESB. Membro da Academia de Ciências da Bahia.

Estrada de São Lázaro, 197. Cep: 40210-730. Federação Salvador - Bahia - Brasil. jcsalles@ufba.br resses da comunidade, pois firmados antes com o sagrado ou o divino.

Também, conservadas suas dimensões, não deixa de ser de interesse científico o conjunto de manifestações religiosas, passíveis de análise exterior, nem deixa de ter interesse religioso a eventual conversão íntima de acadêmicos, que não parecem encontrar, na profissão de sua fé, um obstáculo a suas pesquisas. De modo mais radical, a tensão entre ciência e religião talvez dê testemunho do impasse outrora descrito por Wittgenstein, quando afirmou tanto a irrelevância do discurso científico (incapaz de tocar questões essenciais da vida e de referir-se ao mundo como um todo, do ponto de vista do altíssimo, pois situado no mundo), quanto a ausência de significado da adesão ao mais elevado, cuja relevância irrecusável não satisfaria, contudo, as condições de uma linguagem que esteja em ordem e, por isso, seja capaz de dizer o mundo, de enunciar o que é o caso.

Em meio a essa tensão, este dossiê tem um interesse duplo. Em primeiro lugar, reúne um conjunto de trabalhos de membros da Academia de Ciências da Bahia, que, reconhecendo a importân- 
cia do tema, se mobilizaram em reuniões, ao longo de 2012 e 2013, com debates e exposições, segundo perspectivas diversas. Aqui, portanto, é apresentada uma seleção dos estudos realizados segundo procedimentos característicos da comunidade científica, no grau elevado de sua inserção em uma Academia de Ciências. Vale, então, registrar a singularidade da Academia de Ciências da Bahia, que nada tem da modorra própria de outros centros, sendo hoje um espaço de interação acadêmica. Para esse seu traço contribui, decerto, a liderança do Dr. Roberto Santos, especialmente amparado no dinamismo de outros membros da Academia, a exemplo de Edivaldo Boaventura e Eliane Azevêdo, cujos nomes destacamos como uma justa homenagem, pois esses três membros da Academia foram os primeiros a cobrar a continuidade dos nossos debates, que já geraram, anteriormente, uma publicação sobre ética e ciência. E, como podemos ver, há uma clara continuidade entre a investigação sobre ética e a investigação sobre a religião, ao menos no aspecto mais essencial de ambos os temas tocarem valores e o que, em suma, ressalvada sua ineludível relevância, não se deixa expressar, salvo pelo estudo de suas manifestações exteriores como práticas sociais.

Outro aspecto da Academia de Ciências da Bahia merece ser destacado, pois, acreditamos, explica parte de seu dinamismo. A Academia de Ciências, reconhecendo-se baiana, não se calcou simplesmente em modelos exógenos, que costumam restringir-se às "ciências duras", com raro espaço até para as ciências humanas, que, antes, neles figura por força de concessão magnânima. Nossa Academia de Ciências, ao contrário, abriga todas as dimensões que, na Bahia, atingiram excelência acadêmico-científica e, com isso, representatividade. Logo, em nosso caso, por nossa história e pelo rigor das contribuições científicas nesses campos, a Academia acolhe, inclusive, as artes e a filosofia. Acreditamos que tal acolhimento favorece e exige um clima de debates, bem como temas como o que ora constitui este dossiê.

Em segundo lugar, além de comportar estudos, este dossiê tem o interesse próprio de uma amostra, sendo exemplar de como o tema da religião não deixa indiferentes pesquisadores dedicados ao trabalho científico. Esse vínculo manifestou-se, então, em arco amplo, como bem podem verificar os que apreciarem este dossiê. Com isso, têm aqui lugar tanto a manifestação mais distante, a análise sociológica de um tema religioso, como ainda a pauta mais íntima, aquela capaz de dispor o cientista a uma reflexão que, sem esperança de resposta, o mobiliza com todas suas forças intelectuais e lhe provoca o espanto. Como amostra, nós a julgamos, enfim, significativa em quantidade $\mathrm{e}$ qualidade, sobretudo por seu recorte, que apenas um olhar externo pode doravante estudar e julgar.

Os autores principais são, portanto, membros da Academia de Ciências, com claro destaque acadêmico em suas respectivas áreas. Amílcar Baiardi, professor titular aposentado da Universidade Federal do Recôncavo Baiano (UFRB) e professor da Universidade Católica do Salvador, em seu trabalho sobre a percepção da ciência por líderes religiosos do Recôncavo Baiano (outrora o maior centro comercial da província), contou com a colaboração de doutorandos de seu grupo de pesquisa, Fabiana Mendes e Wellington Rodrigues. O Recôncavo Baiano (para mim, aliás, ainda o centro do universo) comporta uma diversidade de crenças, marcadas quer pela gênese cristã, quer pela origem africana. Convivendo sem conflito, são, contudo, bastante diversas as reações dessas matrizes religiosas a símbolos bem estabelecidos da ciência, reações que o trabalho pretende sistematizar.

Dante Galeffi, professor da Faculdade de Educação da Universidade Federal da Bahia (UFBA), mostra seu refinamento filosófico na leitura cuidadosa de Henri Bergson, que toma como ponto de partida. Escolhe, assim, um dos veios mais ricos na contemporaneidade para interpelar os caminhos diversos do conceito e da intuição. Com isso, com seu fôlego para percorrer o vasto acervo bergsoniano, pode dirigir-se com originalidade às dimensões da Mecânica e da Mística.

O texto de Eliane Azevêdo, professora emérita da Faculdade de Medicina da Bahia (UFBA) e uma de nossas mais destacadas cientistas, com 
reconhecido trabalho em genética, mostra bem como a temática da religião acompanha sua reflexão, a ponto de ela poder recuperar, na vasta tradição ocidental, a intrincada confluência entre saberes religiosos e os interesses da ciência, com o que pôde ainda refletir, de modo instigante, sobre o interesse atual em tal confluência de ciência e religião.

Manuel Veiga, professor emérito da Escola de Música da UFBA, faz aproximar sua investigação de etnomusicólogo do mistério mesmo que faz coevas a religião, a língua e a música. Faz assim, a seu modo (e sem blasfêmia!), obra de genealogia no melhor sentido filosófico, qual seja, o de colher o sentido de um termo, uma ação, uma instituição, no desafio mesmo de sua gênese, quando as forças do tempo retiram um corpo qualquer do limbo da existência, com boas ou más razões.

Pasqualino Magnavita, professor emérito da Faculdade de Arquitetura da UFBA, dialoga com pensadores contemporâneos (em especial, com Deleuze), desdobrando a reflexão no campo da tensão entre saber e poder, por cuja denúncia pode re- sistir à tirania da transcendência, por quaisquer razões com que ela se pretenda vindicar. Com isso, pode falar da perspectiva de um ateísmo, significando-o como uma prática existencial emancipatória.

Enfim, Paulo Costa Lima, professor da Escola de Música da UFBA, serve-se do célebre texto "Ofuturo de uma ilusão", de Sigmund Freud, como ponto de partida de sua reflexão. A partir daí, como é usitado nos trabalhos de Paulo, tudo é surpresa, a começar do contraponto inicial com John Lennon e da fórmula da "libideme", tomada "como equivalente gozosa da episteme epocal proposta por Foucault". E assim, como é próprio do seu texto (e de cada um dos que compõem o Dossiê), podemos deliciar-nos com uma reflexão original, capaz, em seu caso, de incidir sobre a vida e a arte, e também capaz, no caso de todos os textos, de produzir ou provocar "questões urgentes e aparentemente não resolvíveis”.

Recebido para publicação em 14 de agosto de 2013 Aceito em 26 de agosto de 2013

João Carlos Salles - Doutor em filosofia. Professor da Universidade Federal da Bahia. Sua experiência na área de filosofia volta-se, sobretudo, na perspectiva da epistemologia e da filosofia da linguagem, para a história da filosofia moderna e contemporânea, com ênfase no empirismo clássico e na obra de Ludwig Wittgenstein. Com bolsa do CNPq, desenvolve a pesquisa "A gramática da experiência: o anímico na filosofia da psicologia de Wittgenstein”; e, com recursos do PRONEX (FAPESB/CNPq), coordena o projeto Filosofia e Ciências. Além disso, coordena o Grupo de Pesquisa do CNPq Filosofia Moderna e Contemporânea, ao qual se vincula o Grupo de Estudos e Pesquisa Empirismo, Fenomenologia e Gramática. Publicações recentes: Conhecimento e Ação: entre laços teóricos e redes institucionais. Caderno CRH (UFBA. Impresso), v. 25, p. 911, 2012; Percepção e cor. Dois Pontos (UFPR), v. 9, p. 123-133, 2012; Comportamento e Significação: uma nota sobre Wittgenstein e o Behaviorismo. Analytica (UFRJ), v. 15, p. 49-60, 2011; O cético e o enxadrista: significação e experiência em Wittgenstein. 1. ed. Salvador: Quarteto, 2012. v. 1. 208p. 